\title{
ACÚMULO de ÁCIDOS GRAXOS VOLÁTEIS (AGVS) EM REATORES ANAERÓBIOS SOB ESTRESSE: CAUSAS E ESTRATÉGIAS DE CONTROLE
}

\author{
BUILD UP OF VOLATILE FATTY ACIDS (VFA) IN ANAEROBIC REACTORS \\ UNDER STRESS CONDITIONS: CAUSES AND CONTROL STRATEGIES
}

\section{SÉRGIO F. DE AQUINO}

Doutor (Imperial College London). Bolsista Pós-Doc do CNPq no Departamento de Eng. Sanitária e Ambiental

(DESA) - Escola de Engenharia da UFMG

\section{CARLOS A. L. CHERNICHARO}

Doutor (University of Newcastle). Professor Adjunto IV no Departamento de Eng. Sanitária e Ambiental (DESA) - Escola de Engenharia da UFMG

\author{
Recebido: 22/09/04 Aceito: 23/02/05
}

\section{RESUMO}

Este artigo apresenta uma visão integrada das principais causas de acúmulo de ácidos graxos voláteis (AGVs) em reatores anaeróbios. O acúmulo de acetato observado durante as condições de choque de carga e/ou estresse ocorre provavelmente devido às limitações cinéticas dos microrganismos metanogênicos, que é acentuada com a redução do $\mathrm{pH}$. O acúmulo de acetato e hidrogênio na fase líquida pode, por sua vez, desencadear limitaçôes termodinâmicas e conseqüente acúmulo de propionato e butirato. A manutenção de condiçôes ideais de crescimento dos microrganismos metanogênicos é uma estratégia de controle para reduzir o acúmulo de acetato, embora não seja efetiva em reduzir a concentração de hidrogênio dissolvida ao ponto em que não haja limitação sintrófica. As estratégias para mitigação das limitaçôes termodinâmicas poderiam envolver a regulação da concentração de acetato através do uso de resinas ou membranas, e a separação espacial de microrganismos através da granulação ou tratamento em duas fases.

PALAVRAS-CHAVE: Tratamento anaeróbio, estabilidade do processo, cinética, termodinâmica, transferência de massa, dinâmica de população, deficiência nutricional.

\begin{abstract}
This paper presents an integrated approach of the main reasons for the accumulation of volatile fatty acids (VFAs) in anaerobic reactors. The build up of acetate during shock loads and/or stress conditions is likely to occur due to kinetic limitations of methanogenic microrganisms, which is enhanced by $p H$ reduction. Acumulation of acetate and hydrogen in the liquid phase will set the stage for the accumulation of other VFAs, such as propionate and butyrate, due to thermodynamic inhibition. By mantaining the ideal growth conditions for the methanogens it may be possible to reduce the acetate build up, although it may not be effective in reducing the concentration of dissolved hydrogen so that thermodynamic inhibition is avoided. The strategies to mitigate themodynamic inhibition could involve regulation of acetate by means of membrane or resins, and spacial separation of microrganisms by granulation or staging.
\end{abstract}

KEYWORDS: Anaerobic treatment, process stability, kinetics, thermodynamics, mass transfer, population dynamics, nutrients deficiency.

\section{INTRODUÇÃO}

As diversas características favoráveis da tecnologia anaeróbia - baixa produção de sólidos; baixo consumo de energia; baixos custos de implantação e operação; tolerância a elevadas cargas orgânicas; e possibilidade de operação com elevados tempos de retenção de sólidos e baixos tempos de detenção hidráulica, conferem aos reatores anaeróbios um grande potencial de aplicabilidade no tratamento de águas residuárias concentradas e diluídas (Chernicharo, 1997). O uso dessa tecnologia para o tratamento de esgotos domésticos torna-se ainda mais atrativo no Brasil devido as condiçōes climáticas, e de fato o país assume posição de vanguarda no cenário mundial em relação à aceitação e disseminação de reatores anaeróbios, em especial dos reatores de manta de lodo.

As principais desvantagens da tecnologia anaeróbia são relacionadas à remoção de nutrientes (nitrogênio e fósforo) e patógenos; ao fato da demanda química de oxigênio (DQO) residual ser, na maioria dos casos, elevada para atender os estritos limites de emissão estabelecidos na legislação ambiental; e à maior instabilidade dos reatores anaeróbios. Em particular, a estabilidade de reatores anaérobios durante distúrbios, sejam eles devido a choques de carga orgânica e hidráulica, a presença de compostos tóxicos ou a ausência de nutrientes, é um dos aspectos mais importantes para o sucesso operacional de sistemas de tratamento de esgoto. A resposta às condições de instabilidade é considerada por muitos o "Calcanhar de Aquiles” da digestão anaeróbia, o que contribui para a generalização e difusão de preconceitos em relação ao processo, e prejudica o uso disseminado de uma tecnologia viável, sustentável econômica e ecologicamente.

O sucesso para lidar com distúrbios e desequilíbrios em reatores anaeróbios 
depende principalmente da identificação das causas do problema e dos fatores que limitam os processos metabólicos envolvidos, e isso só será efetivamente conseguido a partir do entendimento dos fenômenos físico-químico-biológicos que governam o tratamento anaeróbio. Somente a compreensão detalhada dos fundamentos do processo anaeróbio permitirá a identificação das causas de eventuais distúrbios, suas consequências a médio e longo prazo, bem como a adoção das corretas medidas de controle e prevenção. $\mathrm{O}$ objetivo desse artigo é discutir os fundamentos teóricos da digestão anaeróbia, apontar aspectos que limitam os complexos processos metabólicos envolvidos e que conduzem à maximização da capacidade do sistema, e apontar os fatores mais importantes que precisam ser considerados na operação e controle de reatores anaeróbios durante condiçôes de instabilidade.

\section{FUNDAMENTOS DO TRATAMENTO ANAEROBIO}

O tratamento anaeróbio envolve processos metabólicos complexos, que ocorrem em etapas sequenciais (Figura 1 ), e que dependem da atividade de no mínimo três grupos de microrganismos distintos: i) bactérias fermentativas (ou acidogênicas), ii) bactérias sintróficas (ou acetogênicas) e iii) microorganismos metanogênicos. A maioria dos microrganismos acidogênicos (grupo I, Figura 1) fermentam açúcares, amino-ácidos e ácidos graxos resultantes da hidrólise da matéria orgânica complexa, e produzem consequentemente ácidos orgânicos (principalmente acético, propiônico e butírico), álcoois (etanol), cetonas (acetona), dióxido de carbono e hidrogênio. Microrganismos fermentativos são os primeiros a atuar na etapa sequencial de degradação do substrato, e são os que mais se beneficiam energeticamente (Tabela 1 ). Por causa disso, bactérias acidogênicas possuem baixo tempo mínimo de geração ( -30 minutos) e as mais elevadas taxas de crescimento do consórcio microbiano. Desta forma, a etapa acidogênica só será limitante do processo se o material a ser degradado não for facilmente hidrolisado.

Como os microorganismos fermentativos não dispõem, em condições anaeróbias, de um aceptor final de elétrons (como oxigênio nos processos aeróbios), o substrato orgânico é ao mes-

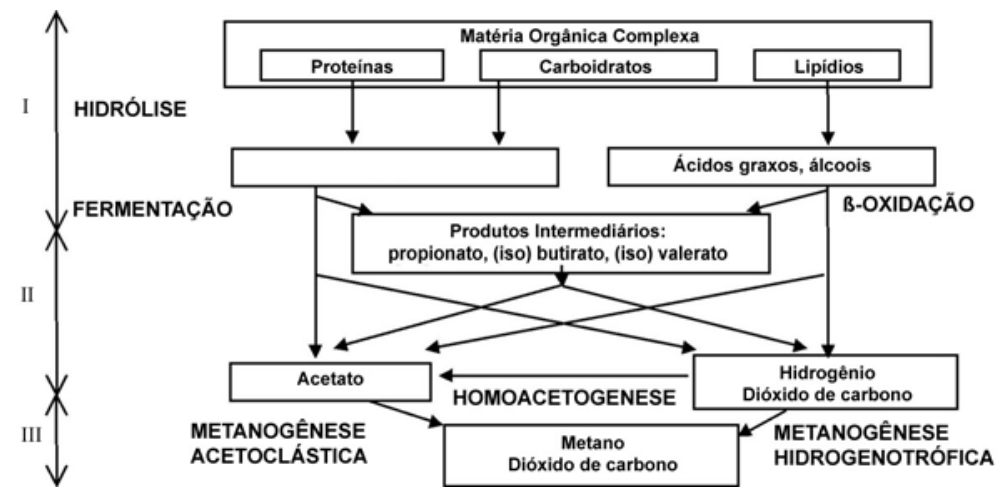

Figura I - Esquema da digestão anaerobia de matéria orgânica complexa, adaptado de Gujer e Zehnder (I983) mo tempo utilizado como aceptor e doador de elétrons, ou seja, uma parte do composto orgânico poluente é oxidada enquanto outra parte é reduzida. A fermentação de $1 \mathrm{~mol}$ de glicose por esse processo produz 2 moles de ácido pirúvico (Figura 2), e como o ácido pirúvico é um composto mais oxidado que a glicose, a sua formação envolve a geração de 2 moles de $\mathrm{NADH}$, que é a forma reduzida do transportador de elétrons $\left(\mathrm{NAD}^{+}\right)$mais comum na degradação de carboidratos. Como há quantidade limitada de $\mathrm{NAD}^{+}$dentro das células, o microorganismo precisa re-oxidar e reciclar o transportador de elétrons se livrando dos 2 elétrons presentes na molécula de NADH. Microorganismos aeróbios fazem essa reciclagem transferindo elétrons do NADH para o oxigênio, o que leva a formação de água, enquanto que microorganismos anaeróbios fermentativos transferem os elétrons do $\mathrm{NADH}$ para a molécula de piruvato, levando à formação de vários compostos reduzidos (principalmente propionato, butirato, hidrogênio, etanol, propanol, formiato) a depender do tipo de microorganismo e das condições ambientais envolvidas (Rittmann e McCarty, 2001).
Do ponto de vista de engenharia é melhor que a reciclagem de NADH seja feita por microorganismos que têm a capacidade de reduzir prótons, produzindo consequentemente hidrogênio que é um gás de baixa solubilidade em água e alto valor energético. Isso porque a canalização de elétrons para a formação de hidrogênio diminuiria a formação de produtos mais reduzidos que acetato (propionato, etanol, butirato) solúveis em água, que além de contribuirem para a DQO no efluente não seriam substratos diretos da metanogênese. Por outro lado, a acumulação de hidrogênio na fase dissolvida pode levar à inibição termodinâmica de importantes conversóes metabólicas. Como exemplo, a reciclagem de $\mathrm{NADH}$ via redução de prótons e produção de hidrogênio é termodinamicamente desfavorável $\left(\Delta \mathrm{G}^{\circ}>0\right)$ nas condiçōes padrão $\left(25^{\circ} \mathrm{C}, 1 \mathrm{~atm}, 1 \mathrm{~mol} / \mathrm{L}\right.$ de reagentes$)$, e é afetada pela concentração de hidrogênio dissolvido (Equação 1).

$\mathrm{NADH}+\mathrm{H}^{+} \rightarrow \mathrm{NAD}^{+}+\mathrm{H}_{2} \Delta \mathrm{G}^{\mathrm{o}}=+18 \mathrm{~kJ} / \mathrm{mol}$

Nesses casos em que a energia livre pradrão é positiva, os processos metabólicos só são termodinamicamente favorácomo será discutido em detalhes adiante,

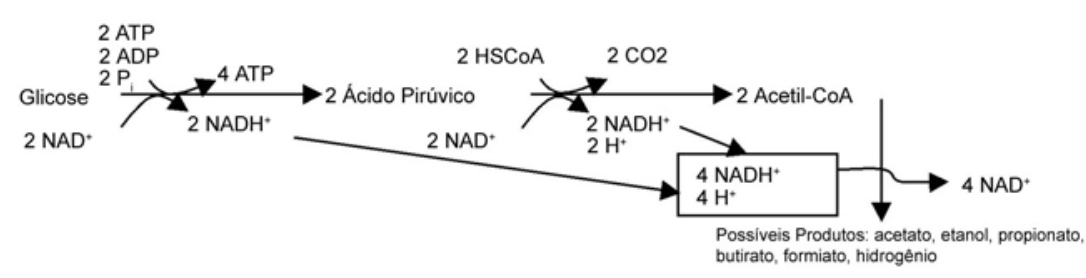

Figura 2 - Conversão de carboidrato (representado pela glicose) a acetil coenzima A 
veis $\left(\Delta \mathrm{G}^{\circ}<0\right)$ nas condiçôes ambientais se os produtos da reação são mantidos em baixas concentraçôes, como pode ser deduzido da Equação 2.

$\Delta G=\Delta G^{o^{\prime}}+R T \ln \frac{[\text { Produtos }]}{[\operatorname{Re} \text { agentes }]}$

Isso é de especial importância em reatores anaeróbios durante choques de carga orgânica, porque nessas condições de excesso de fonte de energia os microorganismos acidogênicos, que são de rápido crescimento, produzirão mais hidrogênio (Tabela 1 , equação 3), contribuindo assim para o esgotamento da capacidade de reciclagem de NADH. Mosey e McCarty (1983) sugeriram que durante condições de excesso temporário de energia há formação de compostos orgânicos mais reduzidos como forma alternativa de disposição de elétrons, o que resulta em menor produção de hidrogênio (Tabela 1, Equaçōes 4 e 5).

Nos reatores anaeróbios, há dois grandes problemas práticos associados à formação de proprionato, butirato e outros compostos mais reduzidos que o acetato. O primeiro é que tais compostos não são substratos diretos dos microorganismos metanogênicos, ou seja, a estabilidade de reatores anaeróbios passa a depender não somente da boa atividade dos microorganismos produtores de metano, mas também dos microorganismos sintróficos. $\mathrm{O}$ segundo é que a atividade de microor- ganismos sintróficos acetogênicos, e consequentemente a produçáo de acetato a partir de propionato e butirato, é termodinamicamente inibida pela presença de relativamente baixas concentrações de hidrogênio dissolvido e de acetato.

Microorganismos sintróficos acetogênicos convertem compostos orgânicos intermediários como propionato e butirato, em acetato, hidrogênio e dióxido de carbono (etapa II, Figura 1), e são assim denominados porque a existência deles depende da atividade de microorganismos consumidores de hidrogênio. A Tabela 1 (reaçôes 6, 7, 8) mostra que as reações acetogênicas não são termodinâmicamente favoráveis nas condiçôes padrão, entretanto elas ocorrem naturalmente em reatores anaeróbios, e isso é possível graças a interação de microorganismos acetogênicos e metanogênicos, como ilustrado pela combinação das reações 6, 9 e 10. A reação global (equação 12) mostra que a conversão de propionato na presença de microorganismos metanogênicos é termodinamicamente favorável, entretanto resulta em apenas $56,6 \mathrm{~kJ} / \mathrm{mol}$ propionato. Essa pequena quantidade de energia tem que ser dividida entre as três espécies de microorganismos envolvidas, i.e. acetogênico (reação 6), metanogênico acetoclástico (reação 9) e metanogênico hidrogenotrófico (Equação 10).
O fato de os microorganismos sintróficos terem que viver com uma limitada quantidade de energia $(-20 \mathrm{~kJ} / \mathrm{mol})$, que é suficiente para a síntese de apenas 1/3 mol de ATP (Schink, 1997), talvez explique as suas baixas taxas de crescimento (de Bok et al, 2004). Para efeito ilustrativo, uma bacteria aeróbia obteria aproximadamente 100 vezes mais energia durante a degradação completa de 1 mol de glicose (Schink, 2002). Como será discutido adiante, as baixas taxas de crescimento de determinadas espécies do consórcio microbiano contribuem para problemas relacionados à estabilidade de reatores anaeróbios, mas, por outro lado, a baixa geração de lodo é uma das grandes vantagens da tecnologia anaeróbia.

Por causa da baixa energia resultante das reações sintróficas, microorganismos acetogênicos são obrigatoriamente produtores de hidrogênio, uma vez que a forma mais 'econômica' de se livrar de elétrons e reciclar $\mathrm{NAD}^{+}$é através da redução de prótons (equação 1). Em outras palavras, microorganismos acetogênicos 'desperdiçam' menos energia formando hidrogênio ao invés de compostos orgânicos mais reduzidos (ethanol, methanol...). Como o $\Delta \mathrm{G}^{\circ}$ das reações acetogênicas é positivo nas condiçôes padrão, as reaçôes acetogênicas só ocorrerão se a concentração de produtos (hidrogênio e acetato) for mantida em baixas concentraçôes pelos microorganismos consumidores de

Tabela I - Comparação energética de algumas reações comuns na degradação anaeróbia

\begin{tabular}{|c|c|c|c|}
\hline Etapa & Reação & $\Delta \mathrm{Go}^{\prime}$ & Eq. \\
\hline \multirow[t]{3}{*}{$\begin{array}{l}\text { Acidogênese } \\
\text { (1) }\end{array}$} & $\begin{array}{l}\mathrm{C}_{6} \mathrm{H}_{12} \mathrm{O}_{6}+2 \mathrm{H}_{2} \mathrm{O} \rightarrow \underset{\text { glicose }}{2 \mathrm{CH}_{3} \mathrm{COO}^{-}+2 \mathrm{CO}_{2}+2 \mathrm{H}^{+}+4 \mathrm{H}_{2}} \\
\text { acetato }\end{array}$ & -206 kJ/reação & 3 \\
\hline & $\begin{array}{l}\mathrm{C}_{6} \mathrm{H}_{12} \mathrm{O}_{6}+2 \mathrm{H}_{2} \rightarrow \underset{3}{\text { glicose }} \underset{\mathrm{CH}_{3} \mathrm{CH}_{2} \mathrm{COO}^{-}+2 \mathrm{H}_{2} \mathrm{O}+2 \mathrm{H}^{+}}{\text {propionato }}\end{array}$ & $-358 \mathrm{~kJ} /$ reação & 4 \\
\hline & 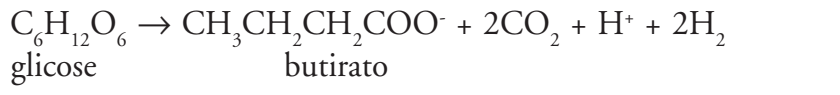 & $-255 \mathrm{~kJ} /$ reação & 5 \\
\hline \multirow[t]{3}{*}{$\begin{array}{l}\text { Acetogênese } \\
\text { (II) }\end{array}$} & $\begin{array}{l}\mathrm{CH}_{3} \mathrm{CH}_{2} \mathrm{COO}^{-}+3 \mathrm{H}_{2} \mathrm{O} \rightarrow \underset{3}{\mathrm{CH}_{3} \mathrm{COO}^{-}+\mathrm{HCO}_{3}^{-}+\mathrm{H}^{+}+3 \mathrm{H}_{2}} \\
\text { propionato }\end{array}$ & +76,1 kJ/reação & 6 \\
\hline & $\begin{array}{l}\mathrm{CH}_{3} \mathrm{CH}_{2} \mathrm{COO}^{-}+2 \mathrm{HCO}_{3}^{-} \rightarrow \underset{\text { propionato }}{\mathrm{CH}_{3} \mathrm{COO}^{-}+\mathrm{H}^{+}+3 \mathrm{HCOO}^{-}} \text {acetato }\end{array}$ & +72,2 kJ/reação & 7 \\
\hline & $\begin{array}{l}\mathrm{CH}_{3} \mathrm{CH}_{2} \mathrm{CH}_{2} \mathrm{COO}^{-}+2 \mathrm{H}_{2} \mathrm{O} \rightarrow \underset{\text { butirato }}{2 \mathrm{CH}_{3} \mathrm{COO}^{-}+\mathrm{H}^{+}+2 \mathrm{H}_{2}} \\
\text { acetato }\end{array}$ & +48,1 kJ/reação & 8 \\
\hline \multirow[t]{3}{*}{$\begin{array}{l}\text { Metanogênese } \\
\text { (III) }\end{array}$} & $\begin{array}{l}\mathrm{CH}_{3} \mathrm{COO}^{-}+\mathrm{H}_{2} \mathrm{O} \rightarrow \underset{\text { acetato }}{\mathrm{CH}_{4}+\mathrm{HCO}_{3}^{-}} \text {metano }\end{array}$ & -31 kJ/reação & 9 \\
\hline & $\begin{array}{l}\mathrm{H}_{2}+1 / 4 \mathrm{HCO}_{3}^{-}+1 / 4 \mathrm{H}^{+} \rightarrow \underset{4}{1 / 4 \mathrm{CH}_{4}}+3 / 4 \mathrm{H}_{2} \mathrm{O} \\
\text { hidrogênio } \\
\text { metano }\end{array}$ & $-33,9 \mathrm{~kJ} /$ reação & 10 \\
\hline & 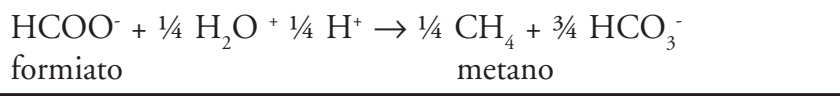 & -32,6kJ/reação & 11 \\
\hline
\end{tabular}




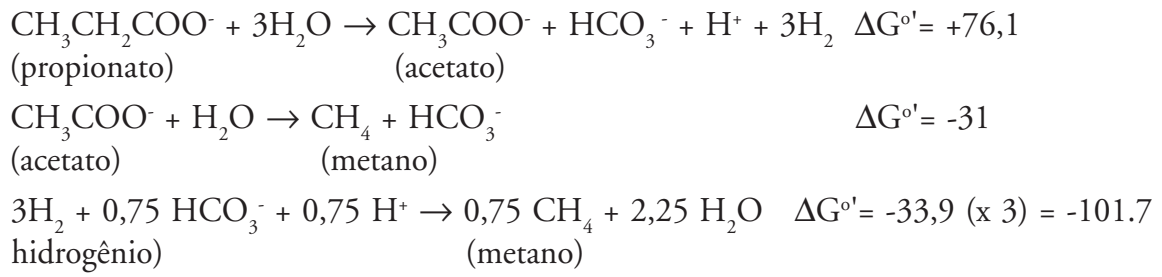

$\mathrm{CH}_{3} \mathrm{CH}_{2} \mathrm{COO}^{-}+1,75 \mathrm{H}_{2} \mathrm{O} \rightarrow 1,75 \mathrm{CH}_{4}+1,25 \mathrm{HCO}_{3}^{-}+0,25 \mathrm{H}^{+} \Delta \mathrm{G}^{\mathrm{o}^{\prime}}=-56,6 \mathrm{~kJ} /$ reação (propionato)

(metano)

acetato e hidrogênio, como exemplificado na equação 12. Em sistemas de tratamento de esgoto, a remoção de hidrogênio da fase líquida é feita principalmente por microorganismos metanogênicos hidrogenotróficos, mas também por bactérias redutoras de sulfato, enquanto que a remoção de acetato só é feita por um grupo de microorganismos que se multiplicam muito lentamente, os metanogênicos acetoclásticos.

Microorganismos metanogênicos acetoclásticos são os mais importantes do consórcio microbiano, porque a remoção de DQO da fase líquida depende da conversão de acetato, composto no qual são canalizados $-70 \%$ dos elétrons do substrato original (McCarty, 1971), em gás metano. Infelizmente esses microorganismos são de lento crescimento, com um tempo de geração mínimo de 2 a 3 dias (Mosey, 1983), e são extremamente dependentes da manutenção de condiçôes ótimas de crescimento. O metano também pode ser produzido a partir de redução de dióxido de carbono (equação 10) ou formiato (equação 11), por microorganismos hidrogenotróficos. A formação de metano por essa via também é conhecida como respiração anaeróbia, porque nesse caso o oxigênio na forma combinada $\left(\mathrm{CO}_{2}\right)$ é utilizado como aceptor de elétrons. Microorganismos metanogênicos hidrogenotróficos são de rápido crescimento, com tempo de geração mínimo de 6 horas (Mosey, 1983), e além de contribuirem para $-30 \%$ do metano formado, a presença deles ajuda a manter baixas concentraçōes de hidrogênio dissolvido em reatores anaeróbios, favorecendo assim a degradação de propionato e butirato (Mosey, 1983; Harper e Pohland, 1986).

\section{DISTÚRBIOS TEMPORARIOS EM REATORES ANAERÓBIOS}

Em um reator estável, operado sob condiçôes ótimas de crescimento microbiano, e na ausência de fatores de estresse, as etapas acidogênica, acetogênica e metanogênica ocorrerão em passos similares, de forma a haver uma equalização nas taxas de produção e consumo dos compostos intermediários. Nesses casos não haverá acumulação significativa de ácidos graxos voláteis (AGVs) e o processo deveria operar próximo às condiçôes de equilíbrio dinâmico. Entretanto, essa condição é raramente observada em estaçōes de tratamento de esgoto, devido às variações na concentração, composição e vazão do afluente, e às mudanças de condições ambientais (temperatura, ausência temporária de nutrientes, presença temporária de compostos tóxicos).

A acumulação de AGVs, principalmente acetato, propionato e butirato, pode ocorrer em sistemas de tratamento em escala real como resultado da não observância das condições ideais de crescimento ou da não observância de limitaçôes cinéticas e termodinâmicas. É importante salientar que a presença de AGVs no efluente reflete uma condição de instabilidade, ao invés de uma deficiência inerente da tecnologia anaeróbia. A acumulação de acetato, propionato e butirato não deve ser encarada como inevitável, mas sim como um sintoma de que uma ou mais etapas do consórcio anaérobio está sendo prejudicada. Os principais fatores que contribuem para a acumulação de AGVs e que determinam o grau de estabilidade de reatores anaérobios durantes condições de distúrbio são discutidos a seguir.

\section{Limitações cinéticas}

A Tabela 2 apresenta dados cinéticos dos principais grupos microbianos que participam do consórcio anaeróbio, podendo-se observar que as bactérias fermentativas apresentam taxa de crescimento muito maior comparada aos outros organismos do consórcio microbiano.

Os valores de $\mathrm{K}$, por sua vez, sugerem que em sistemas tratando esgoto doméstico (DQO na faixa de $100 \mathrm{mg} / \mathrm{L}$ a $500 \mathrm{mg} / \mathrm{L}$ ) os microorganismos acidogênicos e acetogênicos estariam operando abaixo da capacidade máxima ( $\mathrm{K}_{\mathrm{s}}$ indica a concentração de substrato na qual os microorganismos estariam a 50\% do seu crescimento máximo), sugerindo que há capacidade de reserva e que, portanto, a acumulação de propionato e butirato não deveria ser causada por limitaçōes cinéticas, desde que as condiçôes ótimas de crescimento sejam mantidas nos reatores anaeróbios. Obviamente, os microorganismos serão sub-aproveitados se não lhes for dada condições ideais para crescer ( $\mathrm{pH}$ na faixa ideal, presença de nutrientes, ausência de compostos tóxi$\cos$ ), e se houver ainda problemas de difusão de substratos e produtos da solução para ou do interior das células, o que é mais provável de ocorrer em reatores que empregam biofilme ou biomassa na forma de grânulos. Os valores típicos de $\mathrm{K}_{\text {s }}$ apresentados na Tabela 2 sugerem ainda que microorganismos metanogênicos acetoclásticos são facilmente saturados do ponto de vista cinético. Desta forma, durante condiçōes de choque de carga orgânica, onde a produção de acetato atinge valores elevados devido à maior atividade acidogênica, é provável que a acumulação de acetato ocorra devido à saturação dos microoganismos que fazem a conversão de acetato a metano. Ainda que baixos valores de $\mathrm{K}_{\mathrm{s}}$ tenham sido reportados para microorganismos hidrogenotróficos (Tabela 2), é provável que esses microganismos redutores de gás carbônico trabalhem aquém da capacidade máxima, porque a concentração de hidrogênio dissolvido e disponível é geralmente baixa devido às limitações de transferência de massa (Giraldo-Gomez et al, 1992).

Há alguns trabalhos na literatura, com esgotos domésticos e sintéticos, indicando que durante condições de choque de carga orgânica e/ou hidráulica, há um aumento no acúmulo de hidrogênio no biogás (Hickey e Switzenbaum, 1991; Kidby e Nedwell, 1991; Pauss e Guiot, 1993; Cord-Ruwisch et al, 1997). Voolapalli e Stuckey (1999) sugeriram 
Tabela 2 - Resumo das constantes cinéticas para vários substratos durante tratamento anaeróbio mesofilico

\begin{tabular}{|c|c|c|c|c|c|c|}
\hline Substrato & Etapa & $\begin{array}{c}\mathrm{k} \\
(\mathrm{gDQO} / \mathrm{gSSV} \cdot \mathrm{d})\end{array}$ & $\begin{array}{c}\mathrm{K}_{\mathrm{s}} \\
(\mathrm{mg} \mathrm{DQO} / \mathrm{l})\end{array}$ & $\begin{array}{l}\mu_{\max } \\
\left(d^{-1}\right)\end{array}$ & $\begin{array}{c}\mathrm{Y} \\
(\mathrm{gSSV} / \mathrm{gDQO})\end{array}$ & $\begin{array}{c}\mathrm{b} \\
\left(\mathrm{d}^{-1}\right)\end{array}$ \\
\hline Carboidratos & Acidogênica & 1,33 a 70,6 & 22,5 a 630 & 7,2 a 30 & 0,14 a 0,17 & 6,1 \\
\hline $\begin{array}{c}\text { Ácidos de } \\
\text { cadeia longa }\end{array}$ & Oxidação Anaeróbia & 0,77 a 6,67 & 105 a 3180 & 0,085 a 0,55 & 0,04 a 0,11 & 0,01 a 0,015 \\
\hline $\begin{array}{l}\text { Ácidos de } \\
\text { cadeia curta }\end{array}$ & Oxidação Anaeróbia & 6,2 a 17,1 & 12 a 500 & 0,13 a 1,20 & 0,025 a 0,047 & 0,01 a 0,027 \\
\hline Acetato & $\begin{array}{l}\text { Metanogênica } \\
\text { Acetoclástica }\end{array}$ & 2,6 a 11,6 & 11 a 421 & 0,08 a 0,7 & 0,01 a 0,054 & 0,04 a 0,037 \\
\hline $\mathrm{H}_{2} / \mathrm{CO}_{2}$ & $\begin{array}{l}\text { Metanogênica } \\
\text { Hidrogenotrófica }\end{array}$ & 1,92 a 90 & $4,810^{-5 \dagger}$ a 0,6 & 0,05 a 4,07 & 0,017 a 0,045 & 0,088 \\
\hline
\end{tabular}

que a acumulação de hidrogênio em reatores anaeróbios durante choques de carga orgânica não ocorre devido a saturação dos microorganismos hidrogenotróficos, mas sim devido a limitações de transferência de hidrogênio dos microorganismos produtores (acetogênicos) para os consumidores (metanogênicos hidrogenotróficos). Isso é um exemplo de que, ainda que as condiçōes sejam ideais para o crescimento ( $\mathrm{pH}$, nutrientes), ainda que cineticamente os microorganismos não estejam saturados, e ainda que não haja nenhuma limitação termodinâmica, a acumulação de compostos intermediários pode ocorrer devido a limitaçóes de transferência de massa. Recentemente, Pinho (2004) investigou o efeito do tamanho das biopartículas (suporte para crescimento da biomassa) no acúmulo de acetato e propionato em um reator anaeróbio de batelada alimentado com esgoto sintético, e constatou que o acúmulo de acetato e propionato foi maior quando as biopartículas eram menores. Esses resultados contradizem a teoria clássica de transferência de massa que sugere uma proporcionalidade direta entre a resistência à transferência e o tamanho da biopartícula. Entretanto a contradição seria apenas aparente se o acúmulo de acetato e propionato tiver ocorrido por limitaçôes de outra natureza. Isso ilustra o fato de que experimentos similares, feitos por diferentes grupos de pesquisa, podem produzir resultados aparentemente conflitantes. Isso ocorrerá se não se considerar, na interpretação dos resultados, uma análise integrada de fatores cinéticos, termodinâmicos, nutricionais e de transferência de massa.
As diferenças cinéticas entre microorganismos acidogênicos, acetogênicos e metanogênicos causará um desequilíbrio entre produção e consumo de produtos intermediários durante condiçôes de choque de carga orgânica. Isso quase inevitavelmente resultará na acumulação de dióxido de carbono, hidrogênio e acetato, e pode resultar ainda na acumulação de outros AGVs a depender da intensidade do choque e das particularidades do sistema de tratamento empregado. A acumulação de dióxido de carbono contribuirá para o aumento da concentração de ácido carbônico dissolvido, aumentando assim a produção de prótons $\left(\mathrm{H}^{+}\right)$no meio. A acumulação de hidrogênio, por outro lado, pode resultar em maior produção de ácidos orgânicos mais reduzidos, principalmente propionato e butirato, cuja degradação é inibida termodinamicamente pela presença de elevadas concentraçôes de acetato, hidrogênio dissolvido e talvez formiato. A inibição dos microorganismos sintróficos pela acumulação de produtos acidogênicos levará a uma contínua acumulação de $A G V s$, o que contribuirá para o consumo de alcalinidade e decréscimo do $\mathrm{pH}$. Infelizmente a queda do $\mathrm{pH}$ afetará principalmente o crescimento de microorganismos metanogênicos e sintróficos, compondo o problema de acumulação de $A G V$ s e podendo levar à falha do processo. De forma similar, a ausência de nutrientes ou a presença de compostos tóxicos afetará principalmente os microrganismos de lento crescimento, ou seja acetogênicos e metanogênicos acetoclásticos, resultando em sintomas similares aos observados durante as condi- ções de choque, ou seja, acumulação de AGVs e baixa produção de metano.

\section{Limitações termodinâmicas}

Como discutido anteriormente, é provável que a acumulação de acetato em reatores anaeróbios ocorra devido a limitações cinéticas e a não observância das condiçôes ótimas de crescimento dos microorganismos metanogênicos. Por outro lado, a acumulação de propionato e butirato não deveria ocorrer devido a limitações cinéticas, uma vez que há capacidade de reserva. Devido ao fato das reações acetogênicas operarem perto da condição de equilíbrio (DG próximo a zero), elas são facilmente inibidas pelo acúmulo de produtos (acetato, hidrogênio) no meio líquido, e, portanto, é mais provável que o acúmulo de propionato e butirato ocorra devido a limitaçôes termodinâmicas. Entretanto, também é bastante provável que a não observância das condiçōes ótimas de crescimento afete significamente os microorganismos acetogênicos, que de forma similar aos microorganismos metanogênicos, apresentam baixas taxas de crescimento.

McCarty (1981) definiu graficamente os limites termodinâmicos do hidrogênio para as reações acetogênicas (Figura 3), e mostrou que a coexistência de microorganimsos produtores e consumidores só é possível se a pressão parcial de hidrogênio for mantida na região em que a energia livre de Gibbs $(G)$ é negativa para ambos organismos. Desta forma, a oxidação de propionato só é termodinamicamente possível se a pressão parcial 


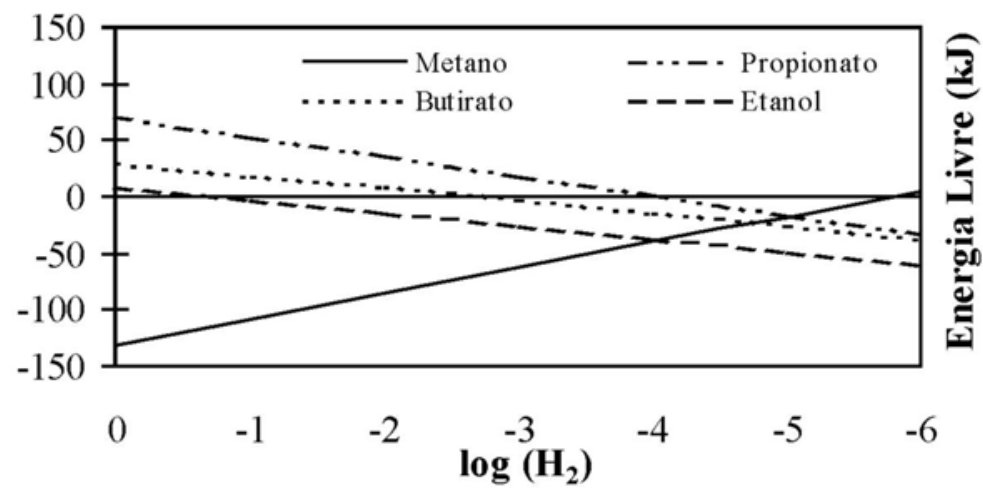

Figura 3 - Efeito da pressão parcial de hidrogênio na variação de energia livre para a degradação de propionato, butirato e etanol e formação de metano (McCarty, 198I)

de hidrogênio for mantida entre $10^{-6} \mathrm{e}$ $10^{-4} \mathrm{~atm}$. O limite máximo de hidrogênio dependerá do substrato a ser degradado, enquanto o limite mínimo dependerá da concentração mínima (threshold value) de hidrogênio utilizável pelos microorganismos hidrogenotróficos. Lovely (1985) foi um dos primeiros a mostrar que há uma concentração mínima de hidrogênio abaixo da qual os microorganismos hidrogenotróficos não conseguem utilizá-lo como substrato. Essa concentração é aquela na qual o investimento de energia que o microorganismo faz para metabolizar o substrato é igual a energia dele obtida.

Voolapali e Stuckey (1999; 2001) mostraram que para os microorganismos hidrogenotróficos a concentração limite é relativamente elevada. Desta forma eles consumirão hidrogênio dissolvido até este valor mínimo que ainda é alto o suficiente para inibir a degradação de propionato e butirato. Assim, qualquer tentativa de melhorar a estabilidade de reatores anaeróbios através da remoção de hidrogênio, para possibilitar a degradação de butirato e propionato, pode comprometer a atividade hidrogenotrófica, o que levaria a uma redução na produção de metano e maior acúmulo de gás carbônico dissolvido. De forma similar, a adição de microorganismos metanogênicos hidrogenotróficos no reator (enriquecimento) poderá não resultar em melhorias significativas, pois é provável que os microorganimos trabalhem bem abaixo de sua capacidade máxima.

Como a degradação sintrófica depende da remoção de hidrogênio do meio líquido, a distância entre os microorganismos produtores e consumidores causa grande efeito na degradação de propionato e butirato (de Bok et al, 2004). Isso ocorre porque hidrogênio é um gás extremamente insolúvel em água, o que resulta em pequeno gradiente de concentração na fase líquida e, consequentemente, reduzida força motriz (driving force) para a transferência de hidrogênio dos microorganismos acidogênicos e acetogênicos para os microorganismos hidrogenotróficos. De fato, vários estudos demostraram que a floculação e granulação da biomassa resulta em maior estabilidade e melhor degradação de propionato e butirato, quando comparado a flocos dispersos e grânulos desestruturados (Shi-Yi e Jian, 1992; Schimidte Ahring, 1993; Schimidt e Ahring, 1995), e acredita-se que isso esteja relacionado à proximidade entre os microor- ganismos produtores e consumidores de hidrogênio.

Embora as reações sintróficas sejam satisfatoriamente modeladas com base na transferência de hidrogênio inter-espécies, há um debate na literatura a respeito da importância do hidrogênio como carreador de elétrons. Thiele e Zeikus (1988) sugeriram que a formação de formiato é um mecanismo de transferência de elétrons inter-espécies tão importante quanto a formação de hidrogênio. Para essa conclusão, os autores se basearam na observação de que as concentrações de hidrogênio dissolvido em reatores anaeróbios são bem menores do que o valor mínimo utilizável (threshold value) pelos microorganismos metanogênicos hidrogenotróficos. Formiato contribui muito menos para a $\mathrm{DQO}$ do que outros AGVs, e por causa disso a transferência de equivalentes de elétrons para a formação de formiato, ao invés de hidrogênio, confereria maior estabilidade a reatores anaeróbios durante condições de choques de carga orgânica (Speece, 1996).

Embora o debate sobre a importância de formiato e hidrogênio como carreadores de elétrons inter-especies seja controverso, Stams (1994) resume o estado-da-arte ao afirmar que em lodo metanogênico granular, a transferência de hidrogênio inter-espécies parece ser mais importante, possivelmente porque quando a distância entre microorganismos produtores e consumidores é pequena (como no grânulo), a fácil difusibilidade de hidrogênio pela membrana lipofílica compensa o pequeno gradiente de concentração de hidrogênio obtido entre microorganismos produtores e consumidores. Entretanto, Stams (1994) salienta que há evidência de que formiato pode ser mais importante que o hidrogênio em culturas suspensas, e isso deve ocorrer porque a elevada solubilidade do formiato favorece um maior gradiente de concentração entre microorganismo produtor e consumidor, compensando a maior distância inter-espécies, e a menor difusibilidade do formiato comparada ao hidrogênio.

\section{Influência do tipo de reator}

A Tabela 3 apresenta as limitaçôes que cada etapa do processo anaeróbio está sujeita do ponto de vista teórico, sumarizando o que foi discutido até aqui. Como pode ser visto, cada etapa do processo apresenta diferentes graus de susceptibilidade às limitaçóes de ordem cinética, termodinâmica e de transferência de massa, ou à ausência das condiçôes ideais de crescimento. Portanto, o sucesso para a estabilidade e controle prático de reatores anaeróbios depende da correta identificação da etapa limitante e da avaliação das suas possíveis causas. Isso permitiria a adoção de medidas adequadas de controle vizando minimizar as limitaçóes existentes e explorar ao máximo a capacidade do sistema de tratamento.

Dois fatores importantes que definem a suceptibilidade do tratamento anaeróbio às limitações apresentadas e discutidas anteriormente, são o tipo de reator e a concentração da água residuária. O tipo de reator tem influência significativa na retenção e estratificação da biomassa, características que determinam limitaçōes de ordem cinéticas e termodinâmicas; ao passo que a concentração $\mathrm{da}$ água residuária influencia principalmente o regime hidráulico predominante, que, por sua vez, determina limitações de ordem termodinâmica e de transferência de massa. Em função disso, a Tabela 4 apresenta um resumo das principais características e limitaçóes que podem ser exibidas por alguns reatores 
Tabela 3 - Susceptibilidade das etapas acidogênica, acetogênica e metanogênica a diferentes limitações

\begin{tabular}{|c|c|c|c|c|}
\hline \multirow[t]{2}{*}{ Etapa } & \multicolumn{4}{|c|}{ Limitação } \\
\hline & Cinética & Termodinâmica & $\begin{array}{c}\text { De transferência } \\
\text { de massa }\end{array}$ & Ao crescimento ${ }^{1}$ \\
\hline Acidogênica & $\begin{array}{c}\text { Pouco provável } \\
\left(\uparrow \mathrm{K}_{\mathrm{s}}, \uparrow \mu_{\max }\right)\end{array}$ & $\begin{array}{l}\text { Possível devido à } \\
\text { acumulação de } \\
\text { acetato }\end{array}$ & $\begin{array}{c}\text { Pouco provável } \\
\text { (substratos solúveis) }\end{array}$ & Menos afetada \\
\hline Acetogênica & $\begin{array}{c}\text { Provável } \\
\left(\downarrow \mathrm{K}_{s}, \downarrow_{\mu_{\text {máx }}}\right)\end{array}$ & $\begin{array}{l}\text { Provável devido à } \\
\text { acumulação de } \\
\text { hidrogênio e acetato }\end{array}$ & $\begin{array}{c}\text { Pouco provável } \\
\text { (substratos solúveis) }\end{array}$ & Muito afetada \\
\hline $\begin{array}{l}\text { Metanogênica } \\
\text { Acetoclástica }\end{array}$ & $\begin{array}{c}\text { Provável } \\
\left(\downarrow K_{s}, \downarrow \mu_{\text {máx }}\right)\end{array}$ & Pouco provável & $\begin{array}{l}\text { Pouco provável } \\
\text { (substrato solúvel) }\end{array}$ & Muito afetada \\
\hline $\begin{array}{l}\text { Metanogênica } \\
\text { Hidrogenotrófica }\end{array}$ & $\begin{array}{c}\text { Pouco provável } \\
\left(\uparrow \mathrm{K}_{\mathrm{s}}, \uparrow_{\mu_{\text {max }}}\right)\end{array}$ & Pouco provável & $\begin{array}{c}\text { Provável } \\
\text { (substrato insolúvel) }\end{array}$ & $\begin{array}{l}\text { Relativamente } \\
\text { menos afetada }\end{array}$ \\
\hline
\end{tabular}

${ }^{1} \mathrm{pH}$, presença de compostos tóxicos, ausência de nutrientes

anaeróbios alimentados com esgoto doméstico e industrial.

Reatores que não propiciam o fluxo pistonado e que favorecem o crescimento disperso, como digestores de lodo convencionais, reatores de membrana, lagoas anaeróbias e reatores UASB, não garantem uma efetiva separação das fases acidogênica, acetogênica e metanogênica. Dessa forma, é provável que o acúmulo de propionato e butirato ocorra nesses reatores durante condições de estresse (choques de carga, presença de compostos tóxicos, limitação nutricional), devido a limitaçôes termodinâmicas causadas pela acumulação de hidrogênio e, principalmente, acetato. Por outro lado, reatores que favorecem o fluxo pistonado, como o reator compartimentado, propiciam uma maior separação de fases e deveriam apresentar maior estabilidade às condiçōes temporárias de estresse porque favoreceriam melhores condiçōes para a degradação de propionato e butirato. Além do mais, a separação espacial dos microorganismos, permitiria que condiçôes ideais fossem mantidas para as diferentes fases, explorando ao máximo o potencial de degradação da biomassa.

Do ponto de vista de uma estação de tratamento alimentada com esgotos domésticos, tipicamente diluídos, a probabilidade de ocorrência de choques de carga orgânica é reduzida. Nesses casos é provável que distúrbios temporários sejam causados por choques hidráulicos ou ausência das condiçóes ideais de crescimento microbiano. Entretanto, choques de carga orgânica poderiam ocorrer nes- sas estações de tratamento se efluentes industriais com elevada carga de matéria orgânica fossem lançados na rede coletora municipal. A ocorrência de tal situação é mais provável em cidades de pequeno porte que abrigam indústrias, tais quais laticínios, curtumes e matadouros, que geram efluentes com elevada carga de DBO.

Como discutido anteriormente, o impacto causado por um choque de carga orgânica seria mais relacionado às limitaçôes cinéticas de degradação do acetato, às limitaçóes termodinâmicas, que causariam o acúmulo de outros AGVs, e à deterioração das condições ideais de crescimento acarretada pelo acúmulo de produtos intermediários. Por outro lado, o impacto de um choque hidráulico não é tão relacionado às limitaçôes termodinâ- micas, de transferência de massa ou de crescimento, mas sim à limitação cinética dos microorganismos metanogênicos e ao arraste da biomassa. No caso do choque de carga orgânica a estratégia de controle para o restabelecimento da condição de equilíbrio depende basicamente da redução das limitações termodinâmicas e da manutenção de boas condições de crescimento. Já o restabelecimento do equilíbro pós-choque hidráulico depende do aumento da quantidade de biomassa no sistema de tratamento, já que a taxa de conversão de intermediários e a taxa de crescimento dos microrganismos são relativamente pequenas. As estratégias de controle para minimização dessas limitações teóricas, ou para a manutenção das condições ideais de crescimento, são discutidas a seguir.

\section{MEDIDAS PRÁTICAS DE CONTROLE}

Há vários estudos, na literatura, sobre melhoria e estabilidade de reatores anaeróbios. Algumas estratégias envolvem a regulação da concentração de hidrogênio e de acetato visando a minimização de inibição termodinâmica, outras objetivam contornar deficiências cinéticas através da adição de lodo enriquecido com organismos metanogênicos, enquanto que a maioria concentra-se na manutenção de condições ideais para os diferentes grupos microbianos através de separação espacial (e.g. compartimentação e reatores de duas fases) e da proteção dos reatores contra toxicidade e efeitos adversos.

Muitas estratégias se baseiam na manutenção das condições ótimas de crescimento dos microorganismos metanogênicos, através da adição de nutrientes (Takashima e Speece, 1990); da regulação do potencial redox com a adição de sulfato ferroso (Thiele e Zeikus, 1988; Borja et al, 1994; Macarie e Guyot, 1995; Mitra et al, 1998); e do monitoramento (on-line) e controle do $\mathrm{pH}$ via remoção de gás carbônico da fase líquida com o uso de membranas (Voolapalli e Stuckey, 1998), ou remoção de gás carbônico da fase gasosa com a purga do headspace do reator com um gás inerte. Essas estratégias de controle assumem que a etapa limitante do processo é a metanogênese, pressupóem que os $A G V$ s serão facilmente convertidos a acetato, e por isso contam com boa atividade dos sintróficos. 
Tabela 4 - Características típicas e limitações teóricas de reatores anaeróbios alimentados com esgoto doméstico

\begin{tabular}{|c|c|c|c|c|c|c|}
\hline \multirow[t]{2}{*}{ Tipo de reator } & \multicolumn{3}{|c|}{ Características práticas } & \multicolumn{3}{|c|}{ Potencial limitação teórica } \\
\hline & $\begin{array}{l}\text { Retenção } \\
\text { biomassa }\end{array}$ & $\begin{array}{c}\text { Separação de } \\
\text { etapas } \\
\text { metabólicas }\end{array}$ & Hidrodinâmica & Cinética & Termodinâmica & $\begin{array}{c}\text { Resistência à } \\
\text { transferência } \\
\text { de massa }\end{array}$ \\
\hline UASB & Média-Alta & $\begin{array}{c}\text { Baixa }^{a} \\
\text { (floculação) }\end{array}$ & Misto $^{\mathrm{b}}$ & Média-Alta & Alta & Média-Baixa \\
\hline Filtro anaeróbio & Média-Alta & $\begin{array}{l}\text { Média-Baixa }^{c} \\
\text { (biofilme) }\end{array}$ & Misto & Média-Alta & Média-Baixa & Alta \\
\hline $\begin{array}{c}\text { Reator de leito } \\
\text { granular } \\
\text { Expandido }\end{array}$ & Média-Alta & $\begin{array}{c}\text { Média } \\
\text { (granulação) }\end{array}$ & $\begin{array}{c}\text { Favorece a } \\
\text { mistura completa }\end{array}$ & Alta & Média & Média-Alta \\
\hline $\begin{array}{c}\text { Reator } \\
\text { compartimentado }\end{array}$ & Média-Baixa $^{\mathrm{d}}$ & $\begin{array}{l}\text { Média-Alta } \\
\text { (granulação e } \\
\text { floculação) }\end{array}$ & $\begin{array}{c}\text { Favorece o } \\
\text { fluxo pistonado }\end{array}$ & Baixa & Média-Baixa & Média-Alta \\
\hline Lagoa anaeróbia & Baixa & $\begin{array}{c}\text { Baixa } \\
\text { (floculação) }\end{array}$ & Misto & Alta & Alta & Baixa \\
\hline $\begin{array}{l}\text { Reator de } \\
\text { membrana }^{\mathrm{e}}\end{array}$ & Alta & $\begin{array}{c}\text { Baixa } \\
\text { (floculação) }\end{array}$ & $\begin{array}{c}\text { Favorece a } \\
\text { mistura completa }\end{array}$ & Alta & Alta & Baixa \\
\hline
\end{tabular}

a - A granulação é difícil de ocorrer com esgotos domésticos, contudo pode ocorrer com esgotos industriais predominantemente solúveis. A granulação favoreceria a separação de fases, contribuindo assim para a redução de inibiçóes termodinâmicas.

b - Para esgotos diluídos, como o doméstico, a produção de gás é, em geral, insuficiente para promover a mistura completa. Entretanto, a mistura completa pode ocorrer com esgotos industriais concentrados, prejudicando a separação de fases e a cinética de degradação. Nesse caso, a separação de etapas metabólicas só ocorreria se houvesse granulação da biomassa e estratificação espacial dos microrganismos no grânulo.

c - A granulação pode não ocorrer com esgotos domésticos, mas a formação de biofilme leva à estratificação dos microorganismos e redução de inibiçôes termodinâmicas. Por outro lado a formação de biofilme pode causar inibições cinéticas devido a maior resistência a transferência de massa.

d - Na ausência de choques hidráulicos há boa retenção de biomassa para relativamente baixos tempos de detenção hidráulica, entretanto a variação de vazão pode causar arraste da biomassa ou promover a mistura completa que contribuiria para inibições termodinâmicas e cinéticas.

e -Reator de mistura completa com uso de membrana ( 0,45 ìm) externa ou submersa.

\section{Regulação de hidrogênio e acetato}

A clássica revisão de Harper e Pohland (1986), baseada na teoria de transferência de hidrogênio inter-espécies, possibilitou o desenvolvimento de novos sistemas de controle da fase gasosa (Harper e Pohland, 1987), uma vez que acreditava-se que a regulação de hidrogênio pudesse resolver os problemas de instabilidade na maioria dos reatores anaeróbios. Harper e Pohland (1987) operaram diferentes reatores sob diferentes condiçōes de carga orgânica e demonstraram que a remoção do biogás nas etapas iniciais da digestão anaeróbia (sistema C, Figura 4) aumentou a estabilidade dos reatores e aumentou a eficiência de remoção de propionato e butirato. $\mathrm{O}$ sistema $A$ foi o que apresentou pior estabilidade durante o aumento da carga, e isso pode ter ocorrido devido à produção acentuada de hidrogênio e inibição termo-
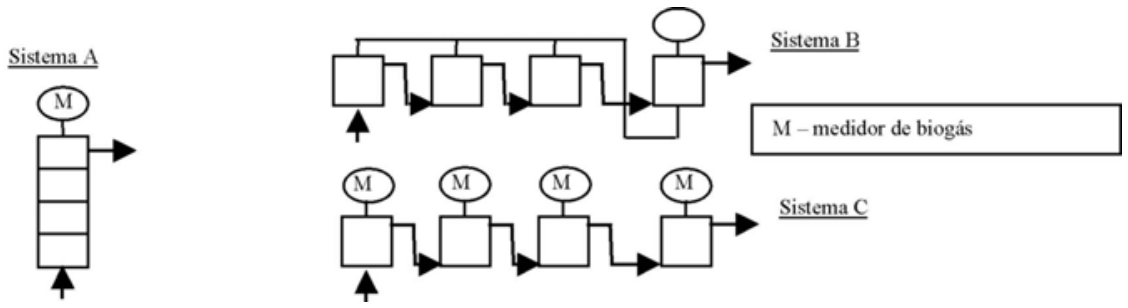

\section{Figura 4 - Três tipos de filtros anaeróbios com diferentes sistemas de remoção de biogás (Harper e Pohland, 1986)}

dinâmica da degradação sintrófica de propionato e butirato.

Em estudo subsequente, Harper e Pohland (1990) apresentaram um resultado controverso ao verificar que a degradação de propionato e butirato foi possível mesmo ao se 'borbulhar' gás hidrogênio no reator, de forma que a sua concentração na fase gasosa fosse 5\%. Entretanto, é preciso ter cautela na interpretação desse resultado, já que a controvérsia pode ser apenas aparente. Isso porque os autores não mediram hidrogênio na fase líquida, ou seja, embora a porcentagem de hidrogênio no biogás fosse alta, a con- centração dissolvida pode ter sido baixa devido à baixa solubilidade de hidrogênio e alta resistência à transferência de massa. Voolapali e Stuckey (1999) fizeram um experimento similar medindo hidrogênio nas fases líquida e gasosa durante o aumento de carga orgânica em digestores anaeróbios, e mostraram que houve aumento da concentração de hidrogênio na fase gasosa com o aumento da carga, muito embora o acúmulo de hidrogênio na fase líquida não tenha ocorrido devido à rápida taxa de consumo (turnover) pelos microorganismos hidrogenotróficos. 
Outra forma de se evitar a inibição termodinâmica e aumentar a estabilidade de reatores anaeróbios é através da regulação de acetato. Mitra e colaboradores $(1998 ; 1998)$ verificaram a possibilidade de se manter uma baixa concentração de acetato em solução, através do uso de resinas de troca iônica. A manutenção de acetato a baixas concentraçôes diminuiria o consumo de alcalinidade e permitiria que a concentração de hidrogênio dissolvido e formiato fossem maiores, $\mathrm{fa}$ vorecendo assim os microrganismos sintróficos por permitir uma maior driving force de hidrogênio/formiato, dos microorganismos produtores para os consumidores. Outras formas de regulação de acetato seriam através da adição de carvão ativado e membranas de adsorção, sendo essa uma área que merece a atenção de futuras pesquisas.

\section{Outras estratégias de controle}

Uma forma de reduzir o acúmulo de acetato em reatores anaeróbios é através da adição de microorganismos metanogênicos acetoclásticos. A adição de lodo rico em microorgamismos acetoclásticos e a manutenção de condiçôes ideais de crescimento do lodo metanogênico aumentariam a taxa de degradação de acetato e a estabilidade do sistema por reduzir inibições termodinâmicas e o consumo excessivo de alcalinidade. Já a adição de lodo enriquecido de microorganismos metanogênicos hidrogenotróficos seria de pouca utilidade, uma vez que a atividade hidrogenotrófica opera abaixo da capacidade máxima e em ponto de sub-saturação cinética, devido às limitaçôes de transferência de massa de hidrogênio. De fato, Voolapali e Stuckey (1999) mostraram que a adição de microorganismos hidrogenotróficos não contribuiu para a redução de hidrogênio na fase gasosa, e que a adição de microorganismos metanogênicos acetoclásticos, por outro lado, contribuiu para a menor acumulação de acetato.

Outra forma de se melhorar a estabilidade de reatores anaeróbios é propiciar o tratamento em estágios (etapas ou fases) por meio da compartimentação de reatores. Há indicaçôes na literatura de que reatores de duas fases são mais estáveis às condiçốes de estabilidade (Cohen et al,1982), justamente porque permitem a separação dos microorganismos e a manutenção das condiçôes ideais para cada nível trófico. Todavia reatores compartimentados podem ser mais susceptíveis a choques hidráulicos, especialmente se não há granulação da biomassa, e podem resultar ainda em maior produção de lodo e maiores dificuldades operacionais. A formação de biofilme e granulação, além de propiciar a complementação de nichos funcionais e a diversidade no reator, resulta em maior redundância metabólica e, consequentemente, em maior estabilidade (Briones e Raskin, 2003). Adicionalmente, a agregação da biomassa em biofilmes e grânulos permite maior proximidade entre os microorganismos do consórcio anaeróbio, diminuindo assim as resistências de transferência de massa, dos produtos intermediários dos organismos produtores para os consumidores, reduzindo por conseguinte inibições termodinâmicas. Por outro lado, essa estratégia pode criar dificuldades para a difusão de nutrientes, da solução para o interior do biofilme ou grânulo, e a deficiência nutricional resultante pode levar à sub-utilização da capacidade metabólica dos microorganismos envolvidos e inibição cinética.

\section{CONCLUSÕES}

Este artigo apresentou uma análise teórica integrada das potenciais causas de acúmulo de ácidos graxos voláteis (AGVs) em reatores anaeróbios. $\mathrm{O}$ acúmulo de AGVs durante condiçôes de instabilidade, sejam elas devido a choques de carga ou a presença de compostos tóxicos, ocorrerá devido a não observância de limitações cinéticas e/ou termodinâmicas, que podem ser causadas por limitaçôes de transferência de massa e/ou nutricionais. A análise teórica indica que os microorganismos metanogênicos acetoclásticos são limitados cineticamente e por isso é provável que ocorra acúmulo de acetato durante choques de carga orgânica. A manutenção, no reator, de altas concentraçôes de acetato e hidrogênio dissolvido podem levar à acumulação de outros AGVs, principalmente propionato e butirato, cuja degradação é facilmente limitada por razôes termodinâmicas. A manutenção de condições ideais de crescimento resolveria o problema de acúmulo de hidrogênio na fase líquida, entretanto é muito difícil reduzir a concentração de hidrogênio dissolvida ao ponto em que não haja limitação sintró- fica. Desta forma, a busca da estabilidade de reatores anaeróbios através da regulação de acetato pode ser promissora, pois resultaria em menor consumo de alcali- nidade e melhores condições para a degradação de compostos intermediários. Este artigo mostra que somente a correta identificação dos fatores limitantes pode levar à adoção das devidas medidas práticas de controle que visam minimizar a acumulação de AGVs e aumentar a estabilidade de reatores anaeróbios.

\section{AGRADECIMENTOS}

Os autores gostariam de agradecer ao $\mathrm{CNPq}$ pela concessão de uma bolsa Pós-Doc (Processo 15004/2004) para o desenvolvimento de atividades de pesquisa junto ao Departamento de Engenharia Sanitária e Ambiental (DESA) da Escola de Engenharia da UFMG.

\section{REFERÊNCIAS}

BORJA, R., BANKS, C. J. e WANG, Z. Stability and performance of anaerobic downflow filter treating slaughterhouse wastewater under transient changes in process parameters. Biotechnology and Applied Biochemistry, vol. 20, p. 371-383, 1994.

BRIONES, A. e RASKIN, L. Diversity and dynamics of microbial communities in engineered environments and their implications for process stability. Current Opinion in Biotechnology, vol. 14, p. 270-276, 2003.

CHERNICHARO, C.A.L. Princípios do tratamento biológico de águas residuárias. Vol. 5. Reatores anaeróbios. Belo Horizonte, Departamento de Engenharia Sanitária e Ambiental - UFMG, 1997.

COHEN, A. et al. Influence of phase separation on the anaerobic digestion of glucose-II. Stability and kinetic response to shock loading. Water Research, vol. 16, p. 449-455, 1982.

CORD-RUWISCH, R. et al. Dissolved hydrogen concentration as an on-line control parameter for the automated operation and optimization of anaerobic digesters. Biotechnology and Bioengineering, vol. 56, p. 626-634, 1997.

DE BOK, F. A. M., PLUGGE, C. M. e STAMS, A. J. M. Interspecies electron transfer in methanogenic propionate degrading consortia. Water Research, vol. 38, p. 1368-1375, 2004.

GIRALDO-GOMEZ, E., GOODWIN, S. e SWITZENBAUM, M. S. Influence of mass transfer limitations on determination of the half saturation constant for hydrogen uptake in a mixed culture methane producing enrichment. Biotechnology and Bioengineering, vol. 40, p. 768-776, 1992.

GUJER, W. e ZEHNDER, A. J. B. Conversion processes in anaerobic digestion. Wat. Sci. Tech., vol. 15 , p. $127-167,1983$.

HARPER, S. R. e POHLAND, F. G. Effect of elevated hydrogen partial pressures on anaerobic treatment of carbohydrates, In: BELAICH, J. P., Microbiology and Biochemistry of Strict Anaerobes Involved in Interspecies Transfer, New York, Plenum Press, p. 387-390, 1990.

HARPER, S. R. e POHLAND, F. G. Enhancement of anaerobic treatment efficiency 
through process modification. Journal of Water Pollution Control Federation, vol. 59, p. 152 $161,1987$.

HARPER, S. R. e POHLAND, F. G. Recent developments in hydrogen management during anaerobic biological wastewater treatment. Biotechnology and Bioengineering, vol. 28 . p. 585-602, 1986 .

HICKEY, R. F. e SWITZENBAUM, M. The response and utility of hydrogen and carbon monoxide as process indicators of anaerobic digesters subjected to organic and hydraulic overloads. Journal of Water Pollution Contro Federation, vol. 63, p. 129-140, 1991.

KIDBY, D. W. e NEDWELL, D. B. $A n$ investigation into the suitability of biogas hydrogen concentration as a performance monitor for anaerobic sewage sludge digesters. Water Research, vol. 25, p. 1007-1012, 1991.

LOVELY, D. R. Minimum threshold for hydrogen metabolism in methanogenic bacteria. Applied and Environmental Microbiology, vol. 49, p. $1530-1531,1985$.

MACARIE, H. e GUYOT, J. P. Use of ferrous sulphate to reduce the redox potential and allow the start up of UASB reactors treating slowly degradable compounds: application to a waste containing 4-methyl benzoic acid. Environmental Technology, vol. 16, p. 1185-1192, 1995.

McCARTY, P. L. Energetics and bacterial growth in organic compounds in aquatic environments, In: Faust, S. D. e Hunter, J. V., New York, Marcel Dekker Inc., 1971.

McCARTY, P. L. History and overview of anaerobic digestion, In: SECOND INTERNATIONAL SYMPOSIUM ON ANAEROBIC DIGESTION, 1981.

MITRA, I. N.et al. Improving stability of anaerobic biological reactors using composite ion exchangers. Water Science and Technology, vol. 38, p. 369-376, 1998.

MITRA, I. N.et al. Evaluating composite ion exchangers (CIX) for improved stability of anaerobic biological reactors. Water Research, vol. 32, p. 3267-3280, 1998.

MOSEY, F. E. Mathematical modelling of the anaerobic digestion: regulatory mechanisms for the formation of short-chain volatile acids from glucose. Water Science and Technology, vol. 15, p. 209-232, 1983.
PAUSS, A. e GUIOT, S. R. Hydrogen monitoring in anaerobic sludge bed reactors at various regimes and loading rates. Water Environment Research, vol. 65, p. 276, 1993.

PAVLOSTATHIS, S. G. e GIRALDOGOMEZ, E. Kinetics of anaerobic treatment: a critical review. Critical Review in Environmental Control, vol. 21, p. 411-490, 1991.

PINHO, S. C. Tratamento de água residuária parcialmente solúvel em reator anaeróbio em batelada sequencial contendo biomassa imobilizada e agitação mecânica: análise da influência da intensidade de agitação e do tamanho de biopartícula, Doutorado, Escola de Engenharia de São Carlos, São Carlos, 2004.

RITTMANN, B. E. e MCCARTY, P. L. Environmental Biotechnology: principles and applications. McGraw-Hill, New York, 2001.

SCHIMIDT, J. E. e AHRING, B. K. Effects of bydrogen and formate on the degradation of propionate and butyrate in thermophilic granules from an upflow anaerobic sludge blanket reactor. Applied and Environmental Microbiology, vol. 59, p. 2546-2551, 1993.

SCHIMIDT, J. E. e AHRING, B. K. Interspecies electron transfer during propionate and butyrate degradation in mesophilic granular sludge. Applied and Environmental Microbiology, vol. 61, p. 2765-2767, 1995.

SCHINK, B. Anaerobic digestion: concepts, limits and perspectives. Water Science and Technology, vol. 45, p. 1-8, 2002

SCHINK, B. Energetics of syntrophic cooperation in methanogenic degradation. Microbiology and Molecular Biology Review, vol. 61, p. 262280, 1997.

SHI-YI, L. e JIAN, C. The contribution of interspecies hydrogen transfer to the substrate removal in methanogenesis. Process Biochemistry, vol. 27, p. 285-289, 1992.

SPEECE, R. E. Anaerobic biotechnology for industrial wastewaters. Archaea Press, 1996.

STAMS, A. J. M. Metabolic interactions between anaerobic bacteria in methanogenic environments. Antonie van Leeuwenhoek, vol. 66, p. 271-294, 1994.

TAKASHIMA, M. e SPEECE, R. E. Mineral requirement for methane fermentation. Critical Reviews in Environmental Control, vol. 19, p. 465-479, 1990.
THIELE, J. H. e ZEIKUS, J. G. The anionexchange substrate shuttle process: a new approach to two-stage biomethanation of organic and toxic wastes. Biotechnology and Bioengineering, vol. 31, p. 521-535, 1988.

THIELE, J. H. e ZEIKUS, J. G. Control of interspecies electron flow during anaerobic digestion: significance of formate transfer versus hydrogen transfer during syntrophic methanogenesis in flocs. Applied and Environmental Microbiology, vol. 54, p. 20-29, 1988.

VOOLAPALLI, R. K. Stability Enhancement of Anaerobic Digestion Through Intermediate Product Regulation, Tese de doutorado, Department of Chemical Engineering and Chemical Technology, London, 1999.

VOOLAPALLI, R. K. e STUCKEY, D. C. Hydrogen production in anaerobic reactors during shock loads: Influence of formate production and $\mathrm{H}_{2}$ kinetics. Water Research, vol. 35, p. 1831$1841,2001$.

VOOLAPALLI, R. K. e STUCKEY, D. C. Relative importance of trophic group concentrations during anaerobic degradation of volatile fatty acids. Applied and Environmental Microbiology, vol. 65, p. 5009-5016, 1999.

VOOLAPALLI, R. K. e STUCKEY, D. C. Stability enhancement of anaerobic digestion through membrane gas extraction under organic shock loads. Journal of Chemical Technology and Biotechnology, vol. 73, p. 153-161, 1998.

Endereço para correspondência:

Sérgio F. Aquino

Escola de Engenharia

Universidade Federal de Minas

Gerais

Departamento de Engenharia

Sanitária e Ambiental

Av. do Contorno, 842 Sala 923

30 I I 0-060 Belo Horizonte - MG -

Brasil

Tel: (3I) 3238-1947

Fax: (3I) 3238-I 879

E-mail: sergio@desa.ufmg.br 